\title{
INTEGRATING DEPENDENCY ON THE LEADER AND EMPOWERMENT INTO TRANSFORMATIONAL LEADERSHIP - CREATIVE PERFORMANCE RELATIONSHIP'
}

\author{
Kollmann, T., Stöckmann, C., Krell, P., Peschl, A. ${ }^{2}$, Buchwald, S.
}

Previous literature highlights employees' creativity as an important means of fostering innovation and competitive advantage in companies. Transformational leadership is an approach aimed at stimulating and encouraging the creative performance of employees. However, contradictory empirical findings indicate that the relationship between transformational leadership and creativity may be more complex than a simple direct link. Drawing from the existing literature, we propose that dependency on the leader is a partial mediator of this relationship, impeding employees' creativity. Synthesizing theories of leadership and creativity, we propose that empowerment, as a moderator, is able to reduce the dependency on the leader caused by transformational leadership as well as contribute to turning possible negative outcomes of transformational leadership on creative performance into positive outcomes. The findings of a PLS analysis of 271 employees support the predicted mediating and moderating effects. Our results indicate that the transformational leadership style should be combined with empowering behavior to enhance employees' creative performance.

JEL Classification: J24

Keywords: transformational leadership; employees' creative performance; dependency on the leader; empowerment

\section{Introduction}

Previous research suggests that enhancing the creative performance of employees is a necessary step for organizations in achieving organizational innovation and competitive advantage (e.g. Amabile, 1988, Lukěs, 2012).

A distinct stream of research focuses on the relationship between leadership and creativity. For example, Redmond, Mumford and Teach (1993) have analyzed the relationship between creativity and leaders' behavior, and Shing and Zhou (2003) have examined the motivational impact on creativity. Although, based on theoretical assertions, transformational leadership should encourage employees' creativity (Bass and Bass, 2008), researchers have found contradictory results concerning the effects of transformational leadership on innovation and creativity (e.g. Shin and Zhou, 2003, cf. Basu and Green, 1997). Those contradictory empirical results indicate that the relationship between transformational leadership and creative performance is more complex than a simple direct link.

Therefore, we propose that transformational leadership increases followers' dependency on the leader (Kark, Shamir and Chen, 2003) and that the latter may decrease followers' creative performance (Yukl, 1998), potentially explaining a total negative effect on creative performance. Further, we propose that empowerment might be an approach to overcoming such negative effects as it enhances the followers' beliefs in their abilities to cope and perform successfully (Kark, Shamir and Chen, 2003). As empowerment is not only positively related to creativity (Conger and Kanungo, 1988) but is also accompanied by independence (Kark, Shamir and Chen, 2003), including empowerment as a moderating variable in the transformational leadership-dependency-creative outcome relationship may contribute to overcoming the limiting effects of transformational leadership.

1 Earlier versions of this paper were presented at the 2011 Academy of Management Annual Meeting, San Antonio, Texas, and the $15^{\text {th }}$ Annual Interdisciplinary Entrepreneurship Conference, St. Gallen/Zurich, Switzerland.

2 Corresponding author 


\section{Transformational Leadership and its Relation to Creativity}

In this paper, we focus on creativity as an outcome of transformational leadership. Transformational leadership theories predict followers' emotional attachment to the leader and the motivational arousal of followers as a consequence of the leaders' behavior (e.g. House, 1977). Furthermore, Bass $(1990,1997)$ defines the transformational leader with the following four terms: charisma (e.g. provides vision and sense of mission); inspiration (e.g. communicates high expectations); intellectual stimulation (e.g. promotes careful problem solving); and individualized consideration (e.g. gives personal attention). Intellectual stimulation, as one of the four terms of transformational leadership, can therefore enhance problem solving.

According to the component model of creativity, problem solving belongs to the component creativity-relevant pro-cesses (Amabile, 1997). The componential theory describes the effects on creativity on the basis of three within-individual components. In addition to creativityrelevant processes, domain-relevant skills and task motivation (intrinsic motivation) belong to the within-individual components (Amabile, 1997). On the one hand, several factors can block creativity, such as a low-risk attitude among top management. On the other hand, other factors can stimulate creativity, such as creativity-encouraging behavior among supervisors and top managers (Amabile, 2012). The link between creativity and the behavior of supervisors shown in this theory gave occasion to examine the outcomes on followers of specific leadership styles.

As mentioned above, transformational leadership is also said to encourage employees' creative performance (Bass and Bass, 2008). Further, empirical research shows that factors associated with transformational leadership, such as support from leaders (e.g. Tierney and Farmer, 2002), feedback (e.g. Zhou and George, 2001), and motivational impact (e.g. Shin and Zhou, 2003) influence creativity. In line with the suggestion of Bass and Bass (2008), for example Shin and Zhou (2003), and Gumusluoglu and Ilsev (2007) found positive effects of transformational leadership on creativity and innovation. However, Basu and Green (1997) found that transformational leadership is negatively related to innovative behaviors among followers, and Wang and Rode (2010) did not find a significant direct effect of transformational leadership on employee creativity. These contradictory empirical results indicate that the relationship between transformational leadership and creative performance is more complex than a simple direct link (e.g. Pillai, Schriesheim and Williams, 1999).

\section{Integrating the Mediating Effect of Dependency on the Leader}

We propose that transformational leadership increases followers' dependency on the leader and that the latter may decrease followers' creative performance (see Eisenbeiß and Boerner, 2013). Followers' dependence on the leader manifests itself as a limited ability to proceed with work and make decisions without the leader's guidance motivation, and as self-esteem depending on receiving recognition and approval from the leader (Kark, Shamir and Chen, 2003). According to Bass (1990, 1997), charisma is counted among the characteristics of transformational leadership. With reference to theories of charismatic leadership, a follower may perceive his or her leader as being extraordinary and exceptional, and therefore might become dependent on the leader for guidance and inspiration (Yukl, 1998). Further, employees see charismatic leaders as role models and followers have a high degree of trust and confidence in transformational leaders (Bass, 1990, see also Bolwby's attachment theory; Popper and Mayseless, 2003).

Psychoanalytic theories, such as the concepts of transference and projection, imply that such leadership styles may result in increased dependency on the leader. One type of transference is called idealization, and is characterized by followers attributing unrealistic qualities to authority figures as leaders and creating an unrealistic image of them. Because of the followers' expectations regarding protection and security by idealized authority figures, dependency on them may accrue (e.g. Kets de Vries, 1988). At first, Kark, Shamir and Chen (2003) find empirical support for the influence of transformational leadership on dependency. While positive evaluations and approval from the leader become important for the followers, the departure of the leader may result in followers' experiencing feelings of loss and distress (Shamir, 1991); not only underlining dependence on the leader but also the followers' inability to depart from the leader's ideas and ideals by way of their own creative innovations. Further, the result of dependence on the leader may be unconditional trust in the leader. Hence, we suggest that this may cause employees to allow themselves to be unrestrictedly led. Therefore, they may not be able to perceive the leader's faults accurately (Kets de Vries, 1988) and thus employees have no need to behave and think autonomously. As a result, distinct problem solving and intrinsic motivation concerning discrete thinking are reduced. Those aspects may lead to reduced creative performance (Amabile, 2012). Finally, according to theories and previous research we propose: 
Figure 1: Conceptual model and hypothesized relationships

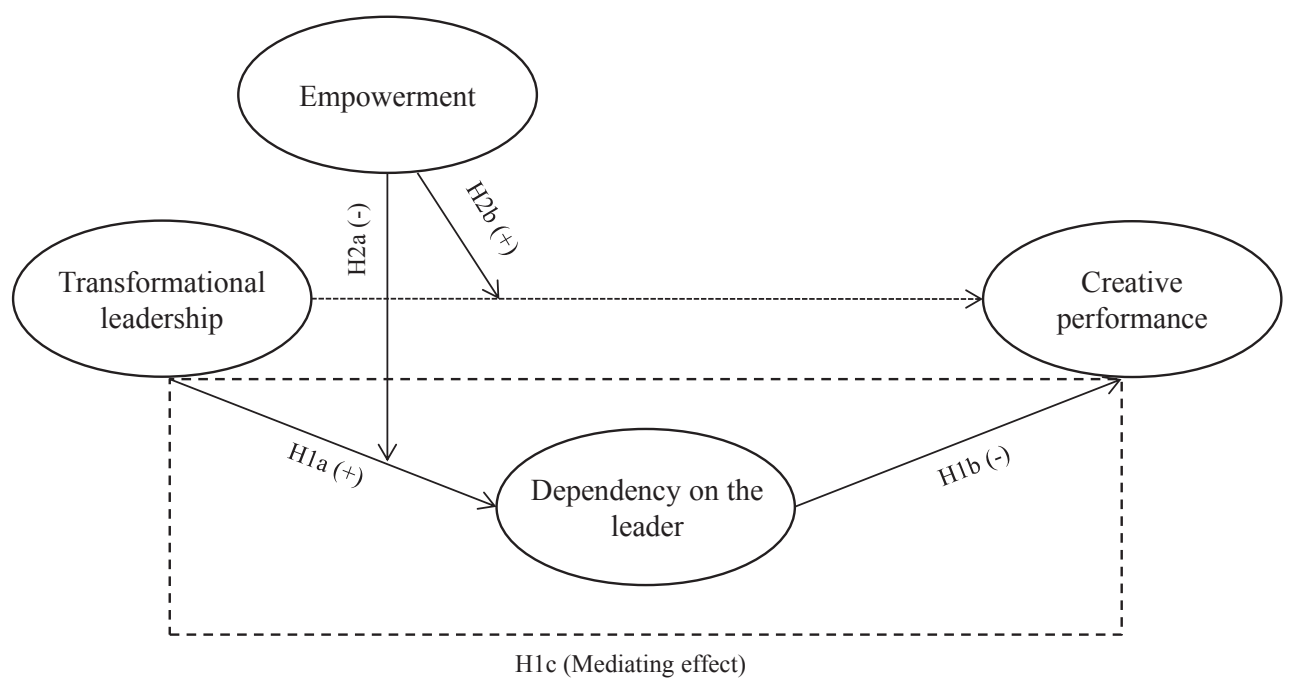

H1a: Transformational leadership has a positive effect on dependency on the leader.

H1b: Dependency on the leader has a negative effect on creative performance.

H1c: Dependency on the leader mediates the relationship between transformational leadership and creative performance.

\section{Integrating the Moderating Effects of Empowerment}

Previous research defines empowerment as managers sharing decision-making power with employees to enhance performance and work satisfaction (e.g. Wagner, 1994). As Forrester (2000: 67) defines it, 'empowerment is a tantalizing notion that seems to offer organizations the promise of more focused, energetic, and creative work from employees. Psychological empowerment has been defined as a multi-dimensional motivational construct consisting of four distinct cognitive dimensions: meaning (value of work goal or purpose); competence (self-efficacy); self-determination (autonomy in initiation and continuation of work behaviors); and impact (influence on work outcomes) (e.g. Thomas and Velthouse, 1990).

In addition to being a direct effect, empowerment is often applied as an intervening variable (e.g. Zhang and Bartol, 2010). Moreover, several researchers have concluded that creativity is fostered when individuals and teams have relatively high autonomy in the day-to-day conduct of their work and a sense of ownership and control over their own work and their own ideas (e.g. Shamir, 1991). As empowerment is not only positively related to creativity (Conger and Kanungo, 1988) but is also accompanied by independence
(Kark, Shamir and Chen, 2003), including empowerment as a moderating variable in the transformational leadership-dependency-creative performance relationship may contribute to overcoming the limiting effects of transformational leadership. On the one hand, empowering leadership may reduce dependency on the leader caused by transformational leadership. The empowerment of employees may result in a feeling of autonomy that buffers dependency as a negative side effect of transformational leadership. On the other hand, empowerment may reinforce the relationship between transformational leadership and creative performance by further allowing ideal space for creative ideas. Formally, we propose:

H2a: Transformational leadership is more likely to engender dependency on the leader when empowerment is low rather than high.

H2b: Transformational leadership is more likely to engender creative performance when empowerment is high rather than low.

Figure 1 summarizes our research model.

\section{Data Collection and Sample}

The sample was disseminated using a German social network platform for business professionals, named Xing. Similar to Fauchart and Gruber (2011), users in related network groups were asked to answer a questionnaire and recommend additional participants.

The sample consisted of 271 employees (107 women) with a mean age of 36.55 years $(S D=8.73)$, ranging from 22 to 61. Their professional experience ranged from 1 year to 40 years with a mean experience of 13.95 years $(\mathrm{SD}=8.87)$. All participants were employed at the point of the data collection. 


\section{Measures}

Transformational leadership: To measure transformational leadership, we applied the revised and extended German version (Felfe and Goihl, 2002) of the Multifactor Leadership Questionnaire (MLQ 5x Short) (Bass and Avolio, 1995). In addition to the original items belonging to the components idealized influence (attributed and behavior, inspirational motivation, individualized consideration and intellectual stimulation, sample item: "My direct supervisor reexamines critical assumptions to question whether they are appropriate.") suggested by Bass (1985), the German revised and extended version encompasses additional items explicitly capturing charisma (Felfe and Goihl, 2002). The final transformational leadership scale consists of 24 items. All variables are measured on 7-point Likert scales ( $1=$ fully disagree, $7=$ fully agree).

Creative performance: Based on Amabile's (1983, 1988) model of employee creativity, we measured creative performance with a modified version of the well-known instrument developed by Zhou and George (2001). In contrast to Zhou and George (2001), we do not rely on supervisor ratings; in fact, we asked the individual employees to rate their own creative performances. The 13 items, such as "Develops adequate plans and schedules for the implementation of new ideas", were measured on 7-point Likert scales (1=fully disagree, $7=$ fully agree).

Dependency on the leader: This study's measure of dependency on the leader is based on the instrument developed by Kark, Shamir and Chen (2003). Out of the instrument's 10 items addressing individual dependence on the leader as well as aspects of dependency on the team level, we slightly adapt eight items addressing individual dependence on the leader to the context of our study, including "If the supervisor goes on vacation, the employees' functioning would deteriorate." The eight items were measured on 7-point Likert scales (1=fully disagree, $7=$ fully agree).

Empowerment: Empowerment was measured according to Spreitzer (1995) by using a multidimensional instrument encompassing meaning, competence, self-determination, and impact. The scale consisted of 12 items, such as, "The work I do is very important to me" (meaning). All items were measured on 7-point Likert scales (1=fully disagree, $7=$ fully agree).

\section{Descriptive Statistics and Evaluation of the Measurement Model}

In this study, we apply a non-parametric approach to structural equation modeling (SEM), namely partial least squares (PLS) SEM, utilizing the software SmartPLS 2.0 (Ringle, Wende and Will, 2005).

First, the reliability and validity of the measurement model has to be ensured. In line with previous literature, we treat meaning, competence, self-determination, and impact as distinct dimensions of the second-order construct empowerment (Spreitzer, 1995). Because of the scant consensus to be found in the literature regarding the exact components comprising transformational leadership (for reviews see e.g. Avolio, Bass and Jung, 1999), we conducted a factor analysis (Principal Axis with Promax rotation method) which shows that the construct has a one-dimensional structure. After eliminating two items from the transformational leadership scale and one item from the dependency scale that had a low correlation with the other items, the measurement model shows satisfactory reliability and validity. Table 1 summarizes the means, standard deviations, Cronbach's alpha values, composite reliability, and AVE, and correlations among all study variables. All Cronbach's alpha values, composite reliabilities, and values for average variance extracted (AVE) are around or exceed the threshold values. Finally, all factor loadings exceed the recommended level. For evidence of discriminant validity, we initially applied principal axis factoring (PAF) with the Promax rotation method. Additionally, we examined bivariate correlations between factors. No inter-factor correlation was above a critical level. Multicollinearity was also tested using a VIF-index, which showed that multicollinearity is not an issue in this study. ${ }^{1}$

1 For detailed information regarding the evaluation of the measurement model, please contact the authors.

Table 1: Means, standard deviations, Cronbach's alphas, composite reliabilities, and correlations among the constructs

\begin{tabular}{|l|c|c|c|c|c|c|c|c|}
\hline & Mean & SD & $\begin{array}{c}\text { Cronbach's } \\
\text { alpha }\end{array}$ & $\begin{array}{c}\text { Composite } \\
\text { reliability }\end{array}$ & AVE & $\mathbf{1 .}$ & $\mathbf{2 .}$ & $\mathbf{3 .}$ \\
\hline 1. Dependency & 2.50 & 1.23 & .90 & .92 & .62 & $-/-$ & & \\
\hline 2. Empowerment & 5.57 & .85 & .89 & .91 & .47 & -.18 & $-/-$ & \\
\hline 3. Transformational leadership & 4.27 & 1.53 & .98 & .98 & .68 & .50 & .30 & $-/-$ \\
\hline 4. Creative performance & 5.67 & .93 & .96 & .96 & .65 & -.32 & .62 & -.01 \\
\hline
\end{tabular}

$p<.001 p<.01 \quad p<.05$ (one-sided test) 
Table 2. Path Coefficients from Partial Least Squares Analysis

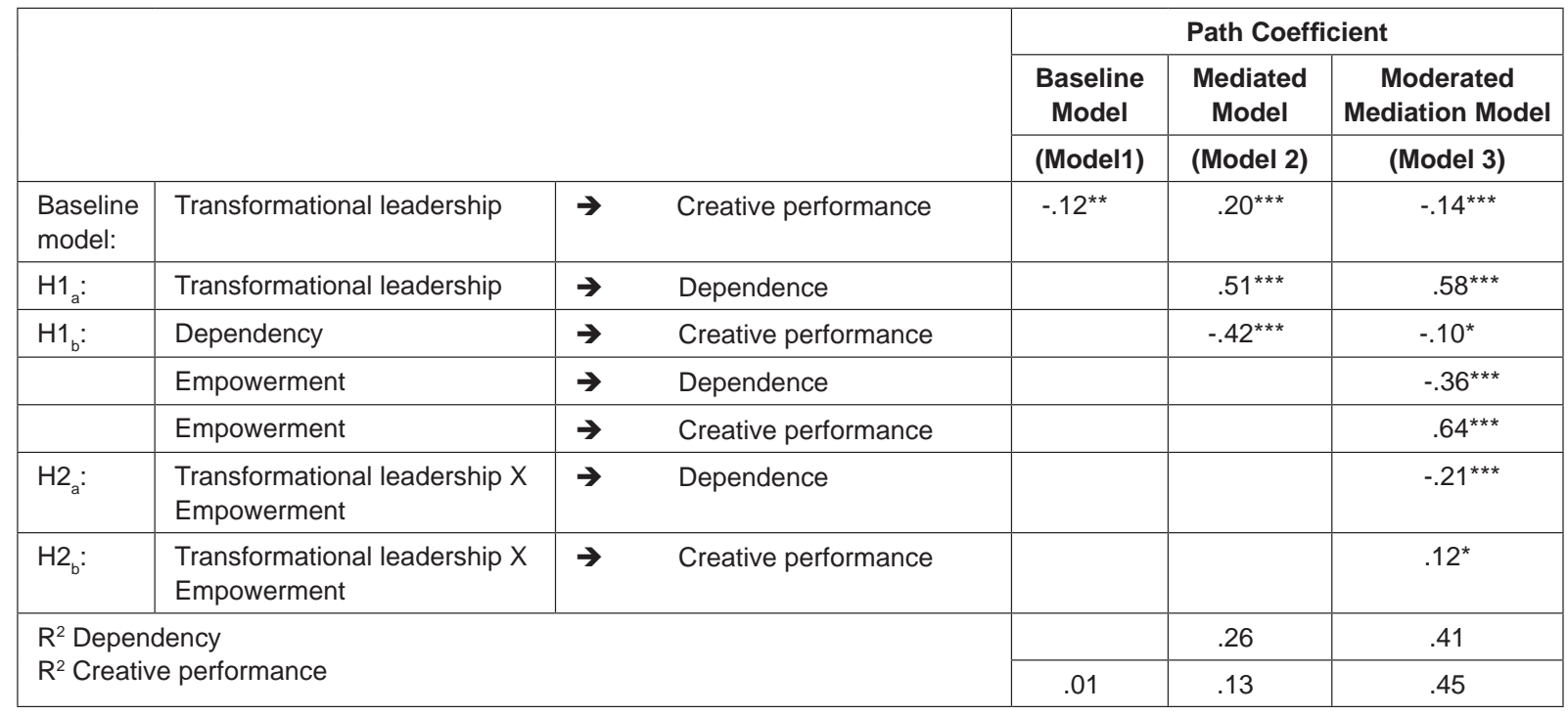

${ }^{\star \star *} p<.001{ }^{* \star} p<.01{ }^{\star} p<.05$ (one-sided test)

Evaluation of Structural Models and Testing of Hypotheses In this section, we present our analysis hierarchically by calculating three different models. We first test a baseline model investigating the direct influence of transformational leadership on creative performance. Second, the dependency construct is introduced as a mediating variable between transformational leadership and creative performance. In the third model, the hypothesized moderating effect of empowerment on the relationship between transformational leadership and creative performance as well as on the link between transformational leadership and dependency complements the mediated model.

In the baseline model (Model 1), transformational leadership $(-.12 ; \mathrm{p}<.01)$ negatively impacts creative performance $\left(\mathrm{R}^{2}=.01\right)$. This preliminary result changes significantly once the dependency construct has been entered into the equation. In this mediated model (Model 2), the independent variables account for 12.9 percent of the variance in creative performance and 25.8 percent of the variance in dependency on the leader. Supporting hypotheses 1a and $1 \mathrm{~b}$, transformational leadership positively affects $(.51 ; \mathrm{p}<.001)$ dependency, while the latter negatively influences $(-.42 ; \mathrm{p}<.001)$ creative performance. The direct effect of transformational leadership on creative performance changes from a negative sign to a significant positive value $(.20 ; p<.001)$. This indicates that dependence on the leader is a negative side effect of transformational leadership, which impedes a possible positive outcome of creative performance. The total effect of transformational leadership on creative performance is still negative, but now non-significant (-.02; $\mathrm{p} \geq .1$ ), hence justifying the inclusion of the dependency variable. A significant Sobel test result $(\mathrm{p}<.001)$ additionally vindicates the assumption of a mediation effect (Baron and Kenny, 1986; Sobel, 1982) and gives support to Hypothesis 1c.

In model 3, the moderating effects of empowerment are added. Supporting hypotheses $2 \mathrm{a}$ and $2 \mathrm{~b}$, empowerment negatively moderates the relationship between transformational leadership and dependency $(-.21 ; \mathrm{p}<.001)$ and positively moderates the relationship between transformational leadership and creative performance $(.12 ; \mathrm{p}<.05)$. In addition to the hypothesized moderating effects, empowerment significantly fosters creative performance $(.64 ; \mathrm{p}<.001)$ and reduces dependency $(-.36 ; \mathrm{p}<.001)$. The relationship between transformational leadership and dependency $(.58 ; \mathrm{p}<.001)$ as well as the relationship between the latter and creative performance $(-.10 ; p<.05)$ change slightly. The sign of the direct effect of transformational leadership on creative performance changes back to negative $(-.14 ; p<.001)$. The total effect of transformational leadership on creative performance is significantly negative $(-.20 ; \mathrm{p}<.001)$. In this moderated mediation model, the independent variables account for 44.6 percent of the variance in creative performance and 40.8 percent of the variance in dependency. Table 2 summarizes the presented results.

\section{Summary and Managerial Implications}

Previous research examined the effect of transformational leadership on employee creativity. Different results concerning this relationship indicate that this relationship is more 
complex than a direct link. The present study aims to further explain the relationship between transformational leadership and creative performance. Based on psychoanalytic theories such as transference and projection, we argued that transformational leadership may lead to an increase in followers' dependency on the leader and that the latter may lead to a decrease in followers' creative performance, preventing a positive effect of transformational leadership on creative performance.

Our empirical results underline this assumption, as the direct effect of transformational leadership turns from a negative sign, which is in line with the results of Basu and Green (1997), to a positive sign when the mediating effect of dependency is partialled out. This indicates dependence is a negative side effect of transformational leadership in terms of the outcome of employee creativity. As hypothesized, our data reveal a significant positive relationship between transformational leadership and dependency as well as a significant negative relationship between the latter and creative performance, which is consistent with the results of Eisenbeiß and Boerner (2013). However, the total effect of transformational leadership on creativity is still negative, but no longer significant. The reason may be that the different signs in the direct and indirect effects can reduce the total effect. Furthermore, our results support our hypotheses that empowerment moderates the relationship between transformational leadership and dependency negatively and the relationship between transformational leadership and creative performance positively, which indicates that empowerment not only reinforces the relationship between transformational leadership and creative performance, but also buffers the link between transformational leadership and dependence on the leader. Hence, empowerment may be viewed as a creativity-encouraging behavior which can stimulate creativity (Amabile, 2012). Both effects are in line with the existing literature, where empowerment in general is accompanied by an increase in independence and creativity is said to be fostered when individuals have relatively high autonomy in the conduct of their work and a sense of ownership and control over their own work and their own ideas (Shamir, 1991). It is important to note that in the full model the sign of the direct effect of the transformational leadership-creative performance linkage turned out to be negative again, which may be caused by the strong direct effect of empowerment on creativity.

In contrast to major previous research (e.g. Bass and Bass, 2008), we postulate that transformational leadership is not compulsory for a creativity-enhancing leadership style. On the one hand, transformational leadership is characterized by motivational behavior towards followers, as empowerment can be beneficial for creative performance (Amabile, 2012). On the other hand, transformational leadership results in emotional attachment and dependence, which can reduce the outcome of creative performance (House, 1977). Our results indicate that this negative side effect of transformational leadership could be reduced by empowerment. Our theory and empirical results provide some interesting findings that contribute to several areas of scholarly discussion and provide some meaningful managerial implications. When transformational leaders aim to encourage creative performance among their employees, they should combine their leadership style with empowerment because the transformational leadership style can create dependency needs among employees (Kets de Vries, 1988). Using this awareness, a transformational leader can counteract dependency as a negative side effect of transformational leadership. This should be considered especially when aiming for organizational innovation to achieve competitive advantage (Amabile, 1988, 1996). Therefore, general managerial competencies such as leadership could be strong predictors of enterprises success (Laguna, Wiechetek and Talik, 2012).

\section{Limitations and Future Research}

The first limitation is that the cross-sectional data do not permit causal inferences about the longitudinal interplay between the variables applied in this study. A longitudinal design, where the variables are measured at different points in time, could give additional insights. Another limitation consists in the design of the survey, as only employees were asked to answer the questionnaire. It would have been better to let the leaders evaluate the creative performances of their followers using objective measures (Zhou and George, 2001). Moreover, future research should consider introducing control variables into the analysis. For example, besides demographic factors such as age and education, individual team longevity (Eisenbeiß and Boerner, 2013) and psychological job complexity (Farmer et al., 2003) may affect creative performance. Further, it should be recognized that employee creative performance may not always lead to the successful implementation of creative ideas at the organizational level, although it often provides the starting point for such innovation (Zhou and George, 2001), which may have a positive effect on firm performance (Kollmann and Stöckmann, 2012). 


\section{References}

Amabile, T. M. (1983). The Social Psychology of Creativity. New York: Springer.

Amabile, T. M. (1988). A model of creativity and innovation in organizations, in Research in organizational behavior, ed. Staw, B., Cummings, M. L., Greenwich, CT: JAI Press, 10: 123-167.

Amabile, T. M. (1997). Motivating Creativity in Organizations: On doing what you love and loving what you do. California Management Review, 40 (1): 39-58.

Amabile, T. M. (2012). Componential Theory of Creativity. Harvard Business School. Working Paper, 12-096.

Avolio, B. J., Bass B. M., Jung, D. I. (1999). Re-examining the components of transformational and transactional leadership using the multifactor leadership questionnaire. Journal of Occupational and Organizational Psychology, 72: 441-462.

Avolio, B. J., Zhu, W., Koh, W., Bhatia, P. (2004). Transformational leadership and organizational commitment: Mediating role of psychological empowerment and moderating role of structural distance. Journal of Organizational Behavior, 25: 951-968.

Baron, R. M., Kenny, D. A. (1986). The moderator-mediator variable distinction in social psychological research: Conceptual, strategic, and statistical considerations. Journal of Personality and Social Psychology, 51: 1173-1182.

Bass, B. M. (1985). Leadership performance beyond expectation. New York: Academic Press.

Bass, B. M. (1990). From transactional to transformational leadership: Learning to share the vision. Organizational Dynamics, 19-31.

Bass, B. M. (1997). Does the transactional-transformational leadership paradigm transcend organizational and national boundaries? American Psychologist, 52 (2): 130-139.

Bass, B. M., Avolio, B. J. (1995). MLQ Multifactor Leadership Questionnaire. Technical report. Redwood City, CA: Mind Garden.

Bass, B. M., Bass, R. (2008). The Bass Handbook of Leadership: Theory, Research, and Managerial Applications. 4th ed., New York: Free Press.

Basu, R., Green, S. G. (1997). Leader-member exchange and transformational leadership: An empirical examination of innovative behaviors in leader-member dyads. Journal of Applied Social Psychology, 27 (5): 477-499.

Conger J. A., Kanungo, R. N. (1988). The empowerment process: Integrating theory and practice. The Academy of Management Review, 13 (3): 471-482.

Dvir, T., Eden, D., Avolio, B. J., Shamir, B. (2002). Impact of transformational leadership on follower development and performance: A field experiment. Academy of Management Journal, 45 (4): 735-744

Eisenbeiß, S. A., Boerner, S. (2013). A double-edged sword: transformational leadership and creative performance. British Journal of Management, 24: 45-68.

Fauchart, E., Gruber, M. (2011). Darwinians, communitarians, and missionaries: The role of founder identity in entrepreneurship. Academy of Management Journal, 54 (5): 935-957.
Farmer, S., Tierney, P., Kung-Mcintyre, K. (2003). Employee creativity in Taiwan: An application of role identity theory. Academy of Management Journal, 46 (5): 618-630.

Felfe, J., Goihl, K. (2002). Deutsche überarbeitete und ergänzte Version des „Multifactor Leadership Questionnaire“ (MLQ), in ZUMA Informationssysteme. Elektronisches Handbuch sozialwissenschaftlicher Erhebungsinstrumente Version 5.00, ed. Glöckner-Rist, A., Frankfurt/Main.

Forrester, R. (2000). Empowerment: rejuvenating a potent idea. Academy of Management Executive, 14 (3): 67-80.

Gumusluoglu, L., Ilsev, A. (2007). Transformational leadership, creativity, and organizational innovation. Journal of Business Research, 62 (4): 461-473.

House, R. J. (1977). A 1976 theory of charismatic leadership. in Leadership: The cutting edge, ed. Hunt, J. G., Larson, L., Carbondale: Southern Illinois: University Press, 189-207.

Kark, R., Shamir, B., Chen, G. (2003). The two faces of transformational leadership: Empowerment and dependency. Journal of Applied Psychology, 88 (2): 246-255.

Kets de Vries, M. F. (1988). Origins of charisma: Ties that bind the leader and the led. in Charismatic leadership, ed. Conger J. A., Kanungo R. N., San-Francisco: JosseyBass, 237-252.

Kollmann, T., Stöckmann, C. (2012). Filling the Entrepreneurial Orientation-Performance Gap: The Mediating Effects of Exploratory and Exploitative Innovations. Entrepreneurship Theory and Practice, 1-26.

Laguna, M., Wiechetek, M., Talik, W. (2012). The Competencies of Managers and Their Business Success. Central European Business Review, 1(3): 7-13.

Mitchell, R. K., Mitchell, J. R., Smith, J. B. (2008). Inside opportunity formation: Enterprise failure, cognition, and the creation of opportunities. Strategic Entrepreneurship Journal, 2: 225-242.

Pillai, R., Schriesheim, C. A., Williams, E. S. (1999). Fairness perceptions and trust as mediators for transformational and transactional leadership: A two-sample study. Journal of Management, 27 (6): 897-933.

Popper, M., Mayseless O., Castelnova, O. (2000): Transformational leadership and attachment. The Leadership Quarterly, 11 (2): 267-289.

Redmond, M. R., Mumford, M. D., Teach, R. (1993). Putting creativity to work: Effects of leader behavior on subordinate creativity. Organizational Behavior and Human Decision Processes, 55: 120-151.

Ringle, C., Wende, S., Will, A. (2005). Smart-PLS 2.0. University of Hamburg, Hamburg.

Rubin, R. S., Munz, D. C., Bommer, W. H. (2005). Leading from within: The effects of emotion recognition and personality on transformational leadership behavior. Academy of Management Journal, 48 (5): 845-858

Shamir, B. (1991). The charismatic relationship: Alternative explanations and predictions. The Leadership Quarterly, 2 (2): 81-102.

Shin, J. S., Zhou, J. (2003). Transformational leadership, conservation, and creativity: Evidence from Korea. Academy of Management Journal, 46 (6): 703-714. 
Singer, M. S., Singer, A. E. (2001). Situational constraints on transformational versus transactional leadership behavior, subordinates leadership preference, and satisfaction. The Journal of Social Psychology, 130 (3): 385-396.

Sobel, M. E. (1982). Asymptotic intervals for indirect effects in structural equations models, in Sociological Methodology, ed. Leinhart, S., San Francisco: Jossey-Bass, 290-312.

Spreitzer, G. M. (1995). Psychological empowerment in the workplace: Dimensions, measurement, and validation. Academy of Management Journal, 38 (5): 1442-1465.

Thomas, K. W., Velthouse, B. A. (1990). Cognitive elements of empowerment: An ,interpretive“" model of intrinsic task motivation. Academy of Management Review, 15 (4): 666-681.

Tierney, P., Farmer, S. M. (2002). Creative self-efficacy: Potential antecedents and relationship to creative performance. Academy of Management Journal, 45 (6): 1137-1148.

Wagner, J. A. III (1994). Participation's effects on performance and satisfaction: A reconsideration of research evidence. Academy of Management Review, 19: 312-330.

Wang, P., Rode, J. C. (2010). Transformational leadership and follower creativity: The moderating effects of identification with leader and organizational climate. Human Relations, 63 (8): 1105-1128.

Woodman, R. W., Sawyer, J. E., Griffin, R. W. (1993). Toward a theory of organizational creativity. Academy of Management Review, 18 (2): 293-321.

Yukl, G. A. (1998). Leadership in Organizations. 4th ed., Englewood Cliffs, New Jersey: Prentice-Hall.

Zhang, X., Bartol, K. M. (2010). Linking empowering leadership and employee creativity: The influence of psychological empowerment, intrinsic motivation, and creative process engagement. Academy of Management Journal, 53 (1): 107-128

Zhou, J., George, J., M. (2001). When job dissatisfaction leads to creativity: Encouraging the expression of voice. Academy of Management Journal, 44 (4): 682-696.
Authors

Prof. Dr. Tobias Kollmann

Full Professor

University of Duisburg-Essen

Universitaetsstr. 9

45141 Essen, Germany

Tel.: +492011832884

Fax: +492011832862

E-mail: tobias.kollmann@uni-due.de

Dr. Christoph Stöckmann

Post-doctoral Researcher

University of Duisburg-Essen

Universitaetsstr. 9

45141 Essen, Germany

Tel.: +492011832628

E-mail: christoph.stoeckmann@icb.uni-due.de

Patrick Krell

Doctoral Researcher University of Duisburg-Essen

Universitaetsstr. 9

45141 Essen, Germany

Anika Peschl

Doctoral Researcher University of Duisburg-Essen

Universitaetsstr. 9

45141 Essen, Germany

Tel.: +492011832815

E-mail: anika.peschl@icb.uni-due.de

Sarah Buchwald

Graduate

University of Duisburg-Essen

Universitaetsstr. 9

45141 Essen 